\title{
Impact of double J stenting or nephrostomy placement during transurethral resection of bladder tumour on the incidence of metachronous upper urinary tract urothelial cancer
}

\author{
Marie C. Hupe ${ }^{1}$, Lukas Dormayer ${ }^{1}$, Tomasz Ozimek¹, Julian P. Struck¹, Martin J. P. Hennig ${ }^{1}$, Melanie Klee ${ }^{1}$,
} Christoph A. J. von Klot ${ }^{2}$, Markus A. Kuczyk ${ }^{2}$, Axel S. Merseburger ${ }^{1}$ and Mario W. Kramer ${ }^{1 *}$

\begin{abstract}
Background: Whether or not double J (DJ) stenting during transurethral resection of a bladder tumour (TURBT) harms patients with regard to possible metachronous upper urinary tract urothelial cancer (UUTUC) development remains controversial. This study evaluated the impact of DJ compared to nephrostomy placement during TURBT for bladder cancer (BCa) on the incidence of metachronous UUTUCs.

Methods: We retrospectively analysed 637 patients who underwent TURBT in our department between 2008 and 2016. BCa, UUTUC and urinary drainage data (retrograde/anterograde DJ and percutaneous nephrostomy) were assessed, along with the prevalence of hydronephrosis, and mortality. Chi-square and Fisher's exact test was performed for univariate analyses. Survival analysis was performed by the Kaplan-Meier method and log-rank tests.

Results: UUTUC was noted in 28 out of 637 patients (4.4\%), whereas only eight (1.3\%) developed it metachronously to BCa. Out of these, four patients received DJ stents, while four patients received no urinary drainage of the upper urinary tract. Placement of urinary drainage significantly correlated with UUTUC $(50.0 \%$ vs. 17.9\%; $p=0.041)$. DJ stenting significantly correlated with UUTUC $(50.0 \%$ vs. $11 \% ; p<0.01)$, while no patient with a nephrostomy tube developed UUTUC. UUTUC-free survival rates were significantly lower for patients with DJ stents than for all other patients $(p=0.001)$. Patients with or without DJ stents had similar overall survival (OS) rates $(p=$ 0.73), whereas patients with nephrostomy tubes had significantly lower OS rates than all other patients $(p<0.001)$.

Conclusions: Patients with DJ stenting during TURBT for BCa might have an increased risk of developing metachronous UUTUC. This study indicated advantages in placing nephrostomy tubes rather than DJ stents; however, confirmation requires investigation of a larger cohort. Even so, the increased mortality rate in the nephrostomy group reflected hydronephrosis as an unfavourable prognostic factor.
\end{abstract}

Keywords: Upper urinary tract urothelial cancer, Double J stent, Nephrostomy, Transurethral resection of bladder tumour

\footnotetext{
* Correspondence: mario.kramer@uksh.de

${ }^{1}$ Department of Urology, University Hospital Schleswig-Holstein, Campus

Luebeck, Ratzeburger Allee 160, 23538 Luebeck, Germany

Full list of author information is available at the end of the article
}

(c) The Author(s). 2020 Open Access This article is distributed under the terms of the Creative Commons Attribution 4.0 International License (http://creativecommons.org/licenses/by/4.0/), which permits unrestricted use, distribution, and reproduction in any medium, provided you give appropriate credit to the original author(s) and the source, provide a link to the Creative Commons license, and indicate if changes were made. The Creative Commons Public Domain Dedication waiver (http://creativecommons.org/publicdomain/zero/1.0/) applies to the data made available in this article, unless otherwise stated. 


\section{Background}

The majority of urothelial cancers (UC) are located in the bladder ( $>90 \%$ ), while $<10 \%$ are upper urinary tract urothelial cancers (UUTUC) [1]. In 17\% of UUTUC patients synchronous bladder cancer (BCa) can also be found [1, 2]. UC recurs in the bladder during follow-up in up to $50 \%$ of all UUTUC patients, i.e., as BCa $[1,3]$. By contrast, only $1.8 \%$ of patients with non-muscle invasive $\mathrm{BCa}$ (NMIBC) show synchronous UUTUC [4], and post-cystectomy upper urinary tract recurrences occur in $<10 \%$ of BCa patients [5-10]. Risk factors for post-cystectomy UUTUC development include history of carcinoma in situ (CIS) or recurrent $\mathrm{BCa}$, cystectomy for NMIBC, and tumour involvement of the distal ureter or prostatic urethra $[7,8,10]$. In addition, risk factors for metachronous UUTUC following $\mathrm{BCa}$ diagnosis include high grade $\mathrm{BCa}$ and tumour localisation at the trigone/ureteral orifice $[11,12]$.

At time of initial diagnosis, 7.5 and $2.1 \%$ of all NMIBC patients present with unilateral and bilateral hydronephrosis, respectively. Among radical cystectomy patients unilateral and bilateral hydronephrosis is present in 19 and 4\%, respectively [9]. Hydronephrosis is known to be associated with advanced $\mathrm{BCa}$, unfavourable survival, as well as recurrence and progression [13-15]. While a nephrostomy tube is placed only in cases of hydronephrosis for drainage, a DJ stent can be placed under the same scenario, but also to protect the ureteral orifice during transurethral resection of a bladder tumour (TURBT), preventing vesicoureteral obstruction.

Kiss et al. retrospectively analysed radical cystectomy patients and indicated a higher risk for metachronous UUTUC in patients who underwent DJ stenting prior to radical cystectomy, compared to a nephrostomy tube or no urinary drainage of the upper urinary tract. Consequently, the authors recommended nephrostomies as preoperative drainage [9].

There are two main hypotheses for an increased UUTUC rate subsequent to DJ stenting during TURBT, enabling tumour cell seeding in the upper urinary tract: (I) a reflux volume between bladder and upper urinary tract, and (II) retrograde manipulation during DJ placement [9]. This study evaluated the impact of placement of a DJ stent compared to a nephrostomy tube during TURBT for BCa on the incidence of metachronous UUTUC.

\section{Methods \\ Cohort}

Figure 1 gives an overview of patient selection for our cohort. Between 2008 and 2016, 2016 TURBTs were performed on 1056 patients at the Department of Urology,

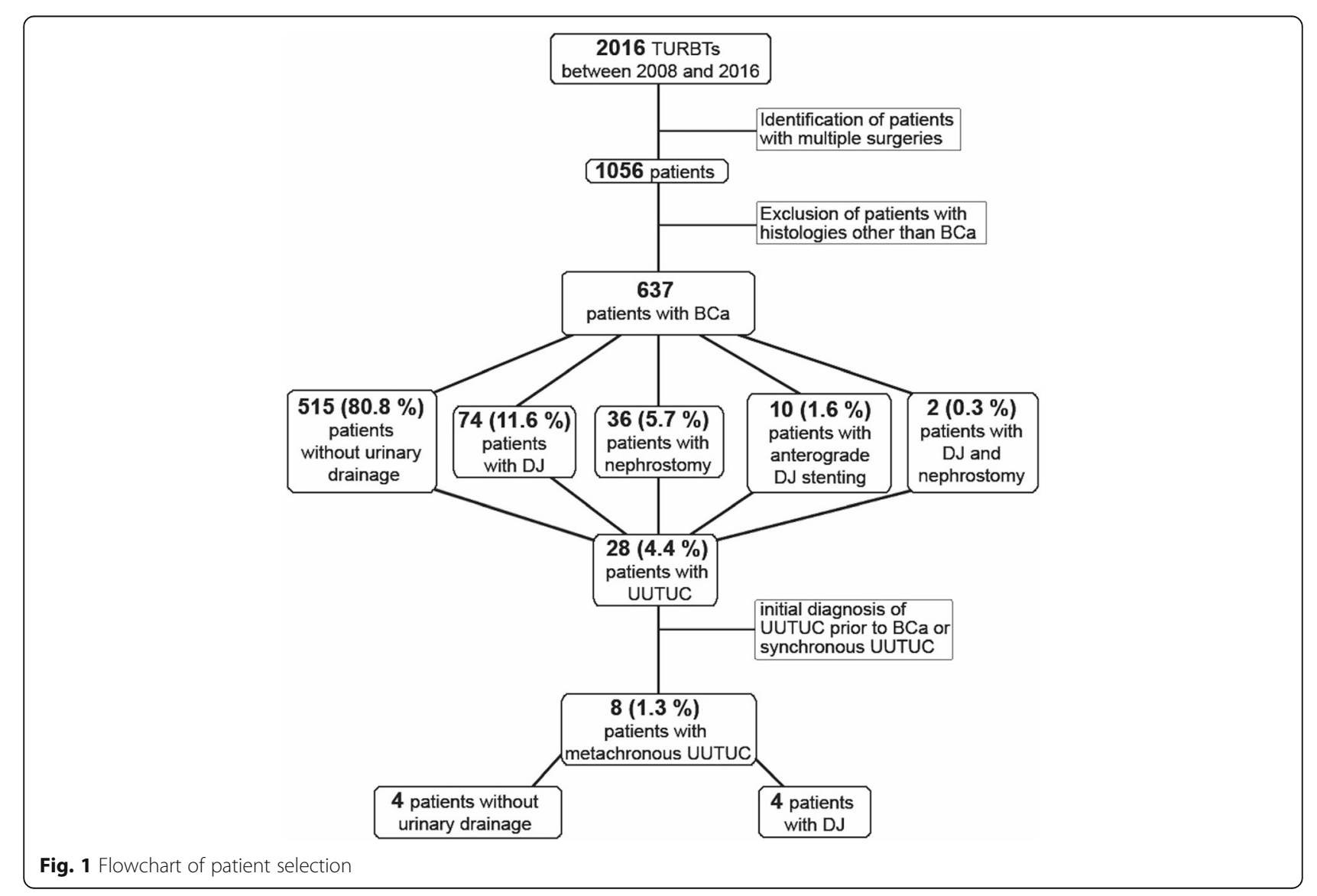



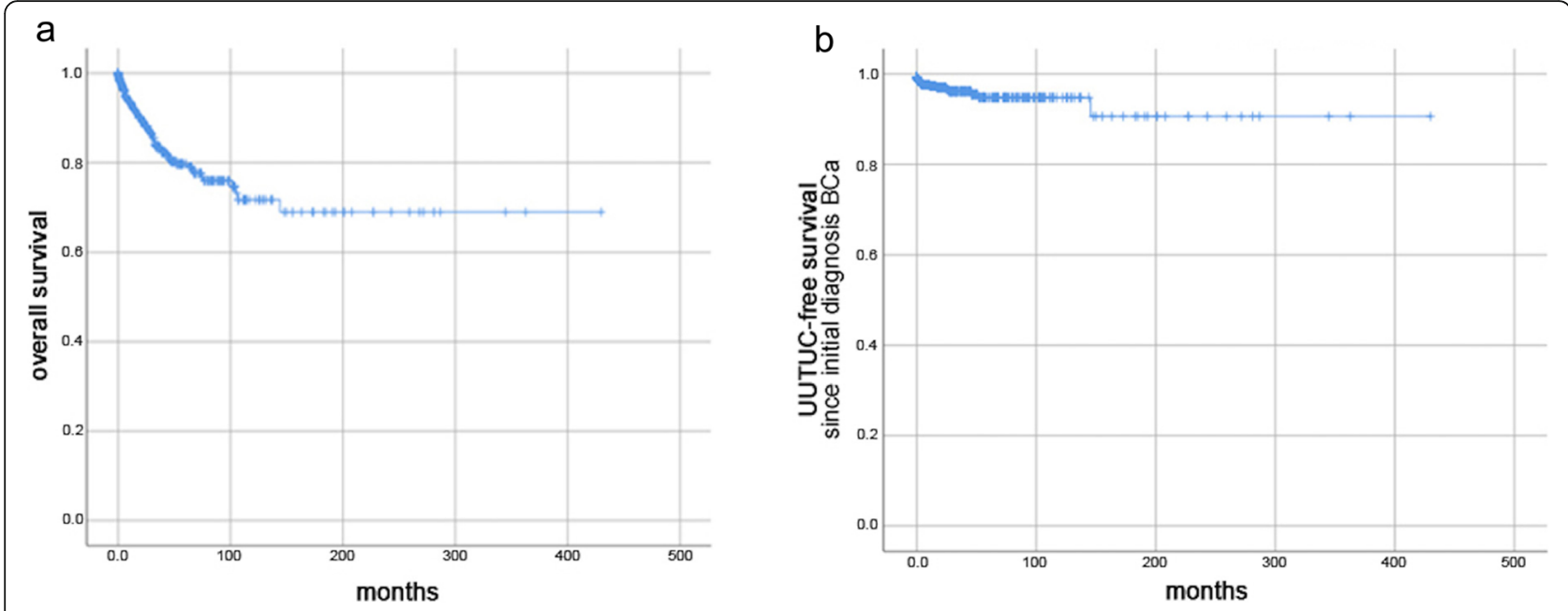

Fig. 2 Survival data of entire cohort. a Overall survival of entire cohort ( $n=637$ patients; 77 events) (b) UUTUC-free survival since initial diagnosis of BCa for entire cohort ( $n=617$ patients; eight events)
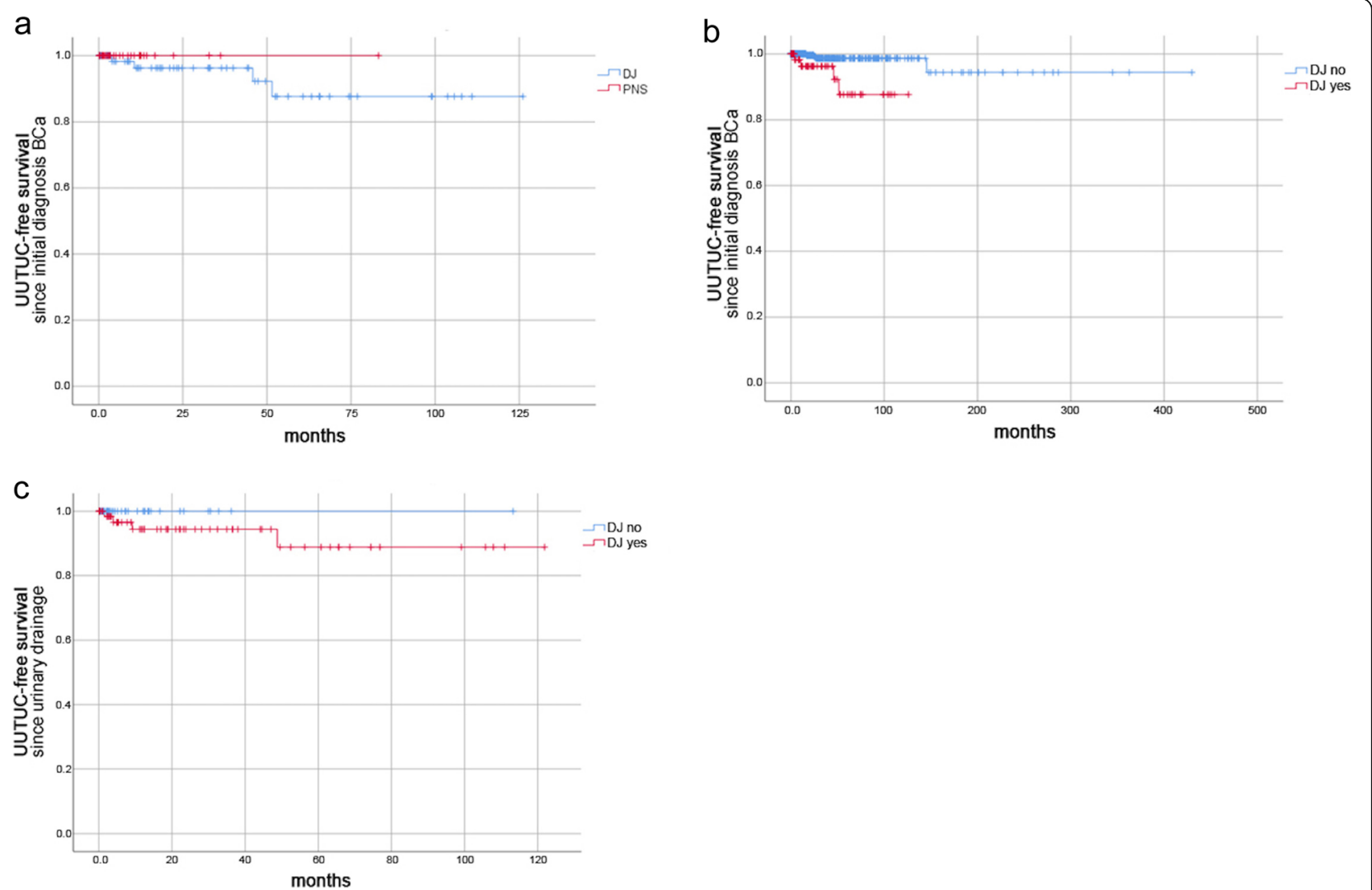

Fig. 3 UUTUC-free survival data according to urinary drainage of the upper urinary tract. a UUTUC-free survival since initial diagnosis BCa for patients with DJ stents compared to those with nephrostomy tubes ( $n=103$ patients; four events; $p=0.415)(\mathbf{b})$ UUTUC-free survival since initial diagnosis BCa for patients with DJ stents compared to those without DJ stents ( $n=617$; eight events; $p=0.001)$ (c) UUTUC-free survival rates since urinary drainage of the upper urinary tract for patients with DJ stents compared to those without DJ stents $(n=113 ;$ four events; $p=0.26)$ 
University Hospital Schleswig-Holstein (UKSH), Luebeck, Germany. Histologies other than $\mathrm{BCa}$, (such as benign histologies, squamous cell carcinoma, adenocarcima; $n=419$ patients) were excluded from the analysis. Variants of urothelial cancers were included. As a result, 637 patients were retrospectively analysed. Ethical approval was obtained from the local ethics committee at the University of Luebeck (17-354A9).

\section{Data collection}

The following parameters were assessed: date of birth; gender; $\mathrm{BCa}$ grading/staging; UUTUC grading/staging/localisation; type of urinary drainage at time of TURBT (retrograde/anterograde DJ, percutaneous nephrostomy) including localisation; and the presence of hydronephrosis including localisation. Date of the last follow-up or death was used for follow-up and Kaplan-Meier analysis. Our analysis included patients who received their initial diagnosis of $\mathrm{BCa}$ prior to 2008, resulting in long follow-up periods (up to 400 months in KaplanMeier curves; Figs. 2, 3 and 4). The oldest diagnosis of BCa was in June 1979. In cases of missing World Health Organization (WHO) 2004 grading, G1 tumours were assigned a low-grade, G3 a high-grade and G2 an unknown grade. Data collection was completed in February 2018. "Metachronous UUTUC" was defined as an UUTUC that developed $>3$ months from diagnosis of $\mathrm{BCa}$ and was diagnosed either by clear radiological evidence or by biopsy.

\section{Statistics}

Statistical analysis was performed with SPSS Statistics for Windows, version 25.0 (IBM Corp., Armonk, NY, USA). For descriptive data, we determined the median and mean with standard deviation. Chi-square analysis and Fisher's exact test (event rates $<10$ ) were performed for categorical variables. Survival analysis was performed by the KaplanMeier method and log-rank tests. Significance was defined as $p<0.05$. UUTUC-free survival was defined as the period between initial diagnosis of $\mathrm{BCa}$, or time of urinary drainage of the upper urinary tract, and either diagnosis of UUTUC, last follow-up or death. Overall survival (OS) was defined as the period between initial diagnosis of $\mathrm{BCa}$
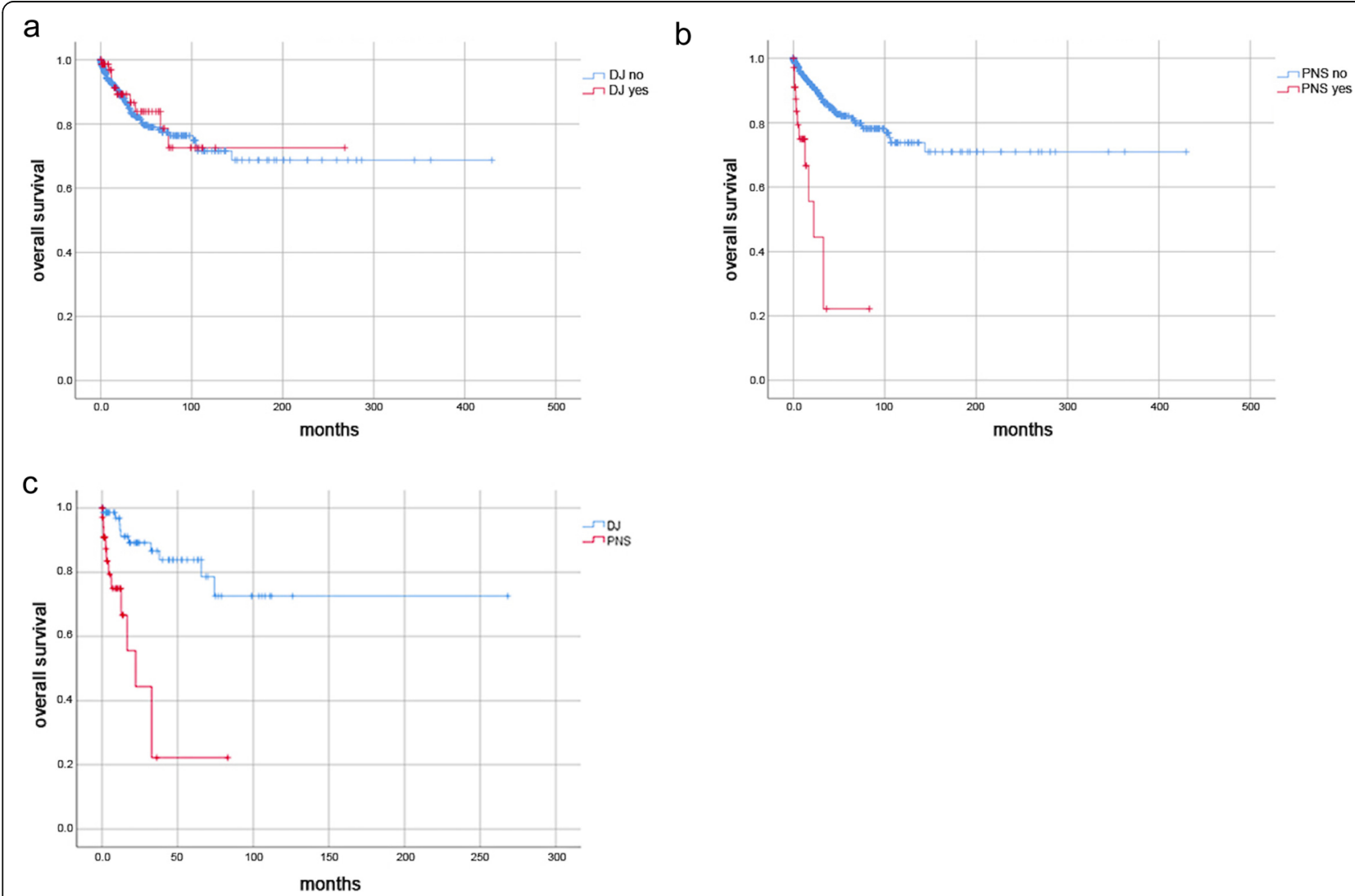

Fig. 4 Overall survival data according to urinary drainage of the upper urinary tract. a Overall survival of entire cohort for patients with DJ stents compared to those without DJ stent $(n=637 ; 77$ events; $p=0.73)$ (b) Overall survival of entire cohort for patients with nephrostomy tubes compared to those without nephrostomy tubes $(n=637 ; 77$ events; $p<0.001)$ (c) Overall survival of entire cohort for patients with DJ stents compared to those with nephrostomy tubes $(n=110 ; 22$ events; $p<0.001)$ 
Table 1 Patient characteristics

\begin{tabular}{l} 
Parameter \\
\hline Gender \\
male \\
female \\
Age at initial diagnosis BCa \\
(mean \pm SD; years) \\
T stage BCa at initial diagnosis \\
pTa \\
PT1 \\
pT2 \\
PT3 \\
PT4 \\
PTis \\
PUNLMP \\
unknown
\end{tabular}

Concomitant CIS at initial

diagnosis

yes

no

Grading (WHO 1973) BCa

at initial diagnosis

G1
G2
G3
unknown

Grading (WHO 2004) BCa

at initial diagnosis

low-grade

high-grade

unknown

Hydronephrosis

no

left

right

bilateral

Urinary drainage of the upper urinary tract

no

DJ

percutaneous nephrostomy

percutaneous nephrostomy for anterograde DJ

percutaneous nephrostomy and DJ

Upper urinary tract urothelial carcinoma (UUTUC)

no

yes
Total $n=637$

$79.4 \%(506 / 637)$

20.6\% (131/637)

$72.5 \pm 11.5$

$41.8 \%(266 / 637)$

$30.0 \%(191 / 637)$

$26.7 \%(170 / 637)$

$0.3 \%(2 / 637)$

$0.2 \%(1 / 637)$

$0.5 \%(3 / 637)$

$0.5 \%(3 / 637)$

$0.2 \%(1 / 637)$

$7.5 \%(48 / 637)$

$92.5 \%(589 / 637)$

$18.7 \%(119 / 637)$

44.4\% (283/637)

$36.6 \%(233 / 637)$

$0.3 \%(2 / 637)$

$20.4 \%(130 / 637)$

$74.9 \%(477 / 637)$

$4.7 \%(30 / 637)$

$86.8 \%(553 / 637)$

$3.8 \%(24 / 637)$

$4.6 \%(29 / 637)$

$4.9 \%(31 / 637)$

$80.8 \%(515 / 637)$

$11.6 \%(74 / 637)$

$5.7 \%(36 / 637)$

$1.6 \%(10 / 637)$

$0.3 \%(2 / 637)$

95.6\% (609/637)

$4.4 \%(28 / 637)$
Table 1 Patient characteristics (Continued)

\begin{tabular}{ll}
\hline Parameter & Total $n=637$ \\
\hline UUTUC prior to BCa & $39.3 \%(11 / 28)$ \\
UUTUC synchronous to BCa & $32.1 \%(9 / 28)$ \\
UUTUC metachronous to BCa & $28.6 \%(8 / 28)$ \\
Death & \\
no & $87.9 \%(560 / 637)$ \\
yes & $12.1 \%(77 / 637)$ \\
\hline BCa bladder cancer, CIS carcinoma in situ, DJ double J stent, PUNLMP papillary \\
$\begin{array}{l}\text { urothelial neoplasm of low malignant potential, SD standard deviation, UUTUC } \\
\text { upper urinary tract urothelial cancer, WHO World Health Organization }\end{array}$
\end{tabular}

and either last follow-up or death. Patients who developed UUTUC prior to or synchronous with $\mathrm{BCa}(n=20)$ were excluded from all UUTUC-free survival analyses.

\section{Data accessibility}

The data supporting the findings of this study are available on request from the corresponding author. The data are not publicly available due to privacy and ethical restrictions.

\section{Results}

\section{Patient characteristics}

Patient characteristics are shown in Table 1 . The majority of patients presented with NMIBC at initial diagnosis (pTa/pT1/pTis: 72.3\%). Concomitant CIS at initial diagnosis was present in $7.5 \%$ of patients. Only $13.3 \%$ of the patients presented with hydronephrosis. Urinary drainage (DJ or percutaneous nephrostomy) was initiated in 19.2\% of patients. In total, 28 out of 637 patients (4.4\%) suffered from UUTUC, whereas only eight patients with UUTUC (1.3\%) developed it during BCa follow-up (i.e. metachronously). Out of these eight patients, four received a DJ stent while the other four received no urinary drainage of the upper urinary tract. Figure 2a shows the OS in our cohort. Figure 2b shows the UUTUC-free survival of our cohort. The median follow-up of our cohort was 14.9 months from initial $\mathrm{BCa}$ diagnosis and 12 months from urinary drainage of the upper urinary tract. At the end of follow-up the mortality rate in the overall cohort was $12.1 \%$ (77/637). Table 2 presents further characteristics of the 17 patients with synchronous or metachronous UUTUC, and Table 3 displays pathological data for the eight patients with metachronous UUTUC.

All four patients with UUTUC and DJ developed UUTUC at the same location (left/right) as the DJ stent was placed (Table 2; patients \#4, 5, 9, and 16). Out of these, one patient without hydronephrosis received bilateral DJ stents, i.e., as a protective measure (patient \#9). Median time from stent placement to UUTUC development for these four patients was 28.2 months. 
Table 2 Characteristics of all 17 patients with synchronous or metachronous UUTUC

\begin{tabular}{|c|c|c|c|c|c|c|c|}
\hline $\begin{array}{l}\text { Patient } \\
\#\end{array}$ & Gender & Hydronephrosis & $\begin{array}{l}\text { Urinary drainage of the } \\
\text { upper urinary tract }\end{array}$ & $\begin{array}{l}\text { Time from diagnosis BCa } \\
\text { to UUTUC (months) }\end{array}$ & $\begin{array}{l}\text { Localisation } \\
\text { UUTUC }\end{array}$ & $\begin{array}{l}\text { T-stage and } \\
\text { grading UUTUC }\end{array}$ & $\begin{array}{l}\text { synchronous (s) vs. } \\
\text { metachronous (m) } \\
\text { UUTUC }^{\mathrm{a}}\end{array}$ \\
\hline 1 & female & bilateral & nephrostomy bilateral & 0.4 & left & $\begin{array}{l}\text { pT4, G2, high- } \\
\text { grade }\end{array}$ & $\mathrm{s}$ \\
\hline 2 & male & left & anterograde DJ left & 2.1 & left & pTis, G3 & s \\
\hline 3 & male & no & no & n.a. & right & pT1, G2, n.a. & n.a. \\
\hline 4 & male & left & DJ left & 45.8 & left & $\begin{array}{l}\text { pTa, G2, high- } \\
\text { grade }\end{array}$ & $\mathrm{m}$ \\
\hline 5 & male & bilateral & DJ bilateral & 10.6 & left & pTa, G1 & $\mathrm{m}$ \\
\hline 6 & male & right & nephrostomy right & 0.2 & right & pT1, G3 & s \\
\hline 7 & male & no & no & 26.9 & right & pT2, G3 & $\mathrm{m}$ \\
\hline 8 & male & left & no & 16.2 & left & pT2, G2, n.a. & $\mathrm{m}$ \\
\hline 9 & male & no & DJ bilateral & 3.9 & right & $\begin{array}{l}\text { pT1, G2, high- } \\
\text { grade }\end{array}$ & $\mathrm{m}$ \\
\hline 10 & female & left & DJ left & 0.2 & left & pT3, G3 & s \\
\hline 11 & male & no & no & 24.9 & left & pTa, G1 & $\mathrm{m}$ \\
\hline 12 & female & right & DJ right & 0.3 & right & $\begin{array}{l}\text { pTa, G2, high- } \\
\text { grade }\end{array}$ & s \\
\hline 13 & male & no & no & 145.5 & left & pTa, G1 & $\mathrm{m}$ \\
\hline 14 & male & right & nephrostomy right & 1.2 & right & pTis, G3 & s \\
\hline 15 & male & right & DJ right & 1.5 & right & pTa, G2, n.a. & s \\
\hline 16 & male & right & DJ right & 51.5 & right & $\begin{array}{l}\text { pT2, G2, high- } \\
\text { grade }\end{array}$ & $\mathrm{m}$ \\
\hline 17 & male & right & no & 2.8 & right & pT2, G2, n.a. & s \\
\hline
\end{tabular}

${ }^{\mathrm{a}}$ Synchronous UUTUC < 3 months from diagnosis of $\mathrm{BCa}$, metachronous $>3$ months from diagnosis of $\mathrm{BCa}$; $B C a$ bladder cancer, $D J$ double J stent, $n . a$. not assessable, UUTUC upper urinary tract urothelial cancer

Table 3 Pathological data of the eight patients with metachronous UUTUC

\begin{tabular}{ll}
\hline UUTUC metachronous to BCa & $n=8$ \\
\hline T-stage UUTUC & \\
pTa & $37.5 \%(3 / 8)$ \\
pT1 & $37.5 \%(3 / 8)$ \\
pT2 & $25.0 \%(2 / 8)$ \\
Grading (WHO 1973) UUTUC & \\
G1 & $25.0 \%(2 / 8)$ \\
G2 & $50.0 \%(4 / 8)$ \\
G3 & $25.0 \%(2 / 8)$ \\
Grading (WHO 2004) UUTUC & \\
low-grade & $25.0 \%(2 / 8)$ \\
high-grade & $62.5 \%(5 / 8)$ \\
unknown & $12.5 \%(1 / 8)$
\end{tabular}

BCa bladder cancer, UUTUC upper urinary tract urothelial cancer, WHO World Health Organization

\section{Parameters correlating with UUTUC}

Presence of hydronephrosis did not significantly correlate with metachronous UUTUC (Table 4). In general, placement of urinary drainage of the upper urinary tract significantly correlated with UUTUC (50.0\% vs. $17.9 \% ; p=0.041)$. No patient with UUTUC had a nephrostomy. DJ stenting significantly correlated with UUTUC (50.0\% vs. $11 \% ; p<0.01)$. Grading and staging at time of initial $\mathrm{BCa}$ diagnosis, or at time of urinary drainage of the upper urinary tract, did not correlate with UUTUC.

UUTUC-free survival rates since initial diagnosis of $\mathrm{BCa}$ were lower for patients with DJ stents than for those with nephrostomy tubes, with no events being recorded for the nephrostomy group (Fig. 3a; $p=0.415$ ). Compared to all other patients, UUTUC-free survival rates since initial diagnosis $\mathrm{BCa}$ for patients with DJ stents were significantly lower (Fig. 3b; $p=0.001$ ). UUTUC-free survival rates since time of urinary drainage of the upper urinary tract were lower for patients with DJ stents, compared to the remaining patients (Fig. 3c; $p=0.26$ ). All metachronous UUTUCs in the group with DJ stents occurred within 5 years of drainage placement. 
Table 4 Parameters correlating with occurrence of UUTUC

\begin{tabular}{llll}
\hline Parameter & No & Metachronous & $p$-value $\left(^{\S}\right.$ \\
& metachronous & UUTUC & Chi-square; \\
& UUTUC & present & $\begin{array}{l}\text { Fisher's } \\
\text { exact })\end{array}$
\end{tabular}

\begin{tabular}{lll}
\hline Hydronephrosis & & \\
no & $87.7 \%(534 /$ & $62.5 \%(5 / 8)$ \\
& $609)$ & \\
yes & $12.3 \%(75 / 609)$ & $37.5 \%(3 / 8)$ \\
Urinary drainage of the & & \\
upper urinary tract & & \\
no & $82.1 \%(500 /$ & $50.0 \%(4 / 8)$ \\
& $609)$ & \\
yes & $17.9 \%(109 /$ & $50.0 \%(4 / 8)$ \\
& $609)$ &
\end{tabular}

Type of urinary drainage

nephrostomy

$65.7 \%(65 / 99) \quad 100 \%(4 / 4)$

DJ

no (incl. nephrostomy)

yes

DJ

no (excl.

nephrostomy)

yes

Nephrostomy

no (incl. DJ)

yes

Nephrostomy

no (excl. DJ)

yes

T-stage BCa at initial diagnosis

$\begin{array}{lll}\text { pTa } & 42.1 \%(253 / & 62.5 \%(5 / 8) \\ & 601) & \\ \text { PT1 } & 30.3 \%(182 / & 37.5 \%(3 / 8) \\ & 601) & \\ \text { pT2 } & 27.6 \%(166 / & 0 \%(0 / 8) \\ & 601) & \\ \text { miscellaneous } & 1.2 \%(8 / 609) & 0 \%(0 / 8)\end{array}$

Grading (WHO 1973)

$\mathrm{BCa}$ at initial diagnosis

$\begin{array}{lll}\text { G1 } & 18.0 \%(109 / & 50.0 \%(4 / 8) \\ & 607) & \\ \text { G2 } & 45.1 \%(274 / & 25.0 \%(2 / 8) \\ & 607) & \\ \text { G3 } & 36.9 \%(224 / & 25.0 \%(2 / 8) \\ & 607) & \\ \text { unknown } & 0.3 \%(2 / 609) & 0 \%(0 / 8)\end{array}$

n.s.

n.s.

$0.041^{\#}$

$0.007^{\#}$

$89.3 \%(544 / \quad 50.0 \%(4 / 8)$

609)

$0.009^{\#}$

n.s.

n.s.
Table 4 Parameters correlating with occurrence of UUTUC (Continued)

\begin{tabular}{llll}
\hline Parameter & $\begin{array}{l}\text { No } \\
\text { metachronous } \\
\text { UUTUC }\end{array}$ & $\begin{array}{l}\text { Metachronous } \\
\text { UUTUC } \\
\text { present }\end{array}$ & $\begin{array}{l}\text { p-value }\left(^{\S}\right. \\
\text { Chi-square; } \\
\text { Fisher's } \\
\text { exact) }\end{array}$ \\
\hline $\begin{array}{l}\text { Grading (WHO 2004) } \\
\text { BCa at initial diagnosis }\end{array}$ & & n.s. \\
low-grade & $\begin{array}{l}20.7 \%(120 / \\
581)\end{array}$ & $50.0 \%(4 / 8)$ & \\
high-grade & $\begin{array}{l}79.3 \%(461 / \\
581)\end{array}$ & $50.0 \%(4 / 8)$ & \\
unknown & $4.6 \%(28 / 609)$ & $0 \%(0 / 8)$ &
\end{tabular}

T-stage BCa at urinary drainage of the upper urinary tract

PTa

$29.5 \%(31 / 105) \quad 75.0 \%(3 / 4)$

$17.1 \%(18 / 105) \quad 25.0 \%(1 / 4)$

$53.3 \%(56 / 105) \quad 0 \%(0 / 4)$

miscellaneous $\quad 3.7 \%(4 / 109) \quad 0 \%(0 / 4)$

Grading (WHO 1973)

$\mathrm{BCa}$ at urinary drainage of the upper urinary tract

$\begin{array}{lll}\text { G1 } & 10.3 \%(11 / 107) & 25.0 \%(1 / 4) \\ \text { G2 } & 41.1 \%(44 / 107) & 50.0 \%(2 / 4) \\ \text { G3 } & 48.6 \%(52 / 107) & 25.0 \%(1 / 4) \\ \text { unknown } & 1.8 \%(2 / 109) & 0 \%(0 / 4)\end{array}$

Grading (WHO 2004)

$\mathrm{BCa}$ at urinary drainage of the upper urinary

tract

$\begin{array}{lll}\text { low-grade } & 10.4 \%(11 / 106) & 25.0 \%(1 / 4) \\ \text { high-grade } & 89.6 \%(95 / 106) & 75.0 \%(3 / 4) \\ \text { unknown } & 2.8 \%(3 / 109) & 0 \%(0 / 4)\end{array}$

n.s.

n.s.

n.s.

Data excludes synchronous UUTUCs; $n=617$; miscellaneous includes BCa staging >pT2, pTis and PUNLMP; "miscellaneous" and "unknown" categories were excluded from statistical analyses

$B C a$ bladder cancer, DJ double J stent, n.s. not significant, UUTUC upper urinary tract urothelial cancer, WHO World Health Organization

\section{Parameters correlating with mortality}

Presence of hydronephrosis, and urinary drainage of the upper urinary tract in general, significantly correlated with death (both $p<0.0001$; Table 5). However, while nephrostomy tubes as urinary drainage significantly correlated with death $(p<0.0001)$, this was not the case for DJ stenting. Advanced T-stage and grading at initial diagnosis also significantly correlated with death $(p<0.0001$ and $p<0.03)$. UUTUC (prior to $\mathrm{BCa}$, synchronous or metachronous) did not correlate with death. From Kaplan-Meier analysis, patients with or without DJ stents had similar OS rates (Fig. 4a; $p=$ 0.73), whereas patients with nephrostomy tubes had 
Table 5 Parameters correlating with mortality

\begin{tabular}{|c|c|c|c|}
\hline Parameter & Patient survived & Patient died & $p$-value $\left({ }^{\S}\right.$ Chi-square; ${ }^{\#}$ Fisher's exact $)$ \\
\hline Hydronephrosis & & & $<0.0001^{\S}$ \\
\hline no & $89.1 \%(499 / 560)$ & $70.1 \%(54 / 77)$ & \\
\hline yes & $10.9 \%(61 / 560)$ & $29.9 \%(23 / 77)$ & \\
\hline Urinary drainage of the upper urinary tract & & & $<0.0001^{\S}$ \\
\hline no & $83.0 \%(465 / 560)$ & $64.9 \%(50 / 77)$ & \\
\hline yes & $17.0 \%(95 / 560)$ & $35.1 \%(27 / 77)$ & \\
\hline Type of urinary drainage & & & $0.015^{\S}$ \\
\hline DJ & $72.7 \%(64 / 88)$ & $45.5 \%(10 / 22)$ & \\
\hline nephrostomy & $27.3 \%(24 / 88)$ & $54.5 \%(12 / 22)$ & \\
\hline DJ (incl. nephrostomy) & & & n.s. \\
\hline no & $88.6 \%(496 / 560)$ & $87.0 \%(67 / 77)$ & \\
\hline yes & $11.4 \%(64 / 560)$ & $13.0 \%(10 / 77)$ & \\
\hline DJ (excl. nephrostomy) & & & n.s. \\
\hline no & $88.1 \%(472 / 536)$ & $84.6 \%(55 / 65)$ & \\
\hline yes & $11.9 \%(64 / 536)$ & $15.4 \%(10 / 65)$ & \\
\hline Nephrostomy (incl. DJ) & & & $<0.0001^{\S}$ \\
\hline no & $95.7 \%(536 / 560)$ & $84.4 \%(65 / 77)$ & \\
\hline yes & $4.3 \%(24 / 560)$ & $15.6 \%(12 / 77)$ & \\
\hline Nephrostomy (excl. DJ) & & & $<0.0001^{\S}$ \\
\hline no & $95.2 \%(472 / 496)$ & $82.1 \%(55 / 67)$ & \\
\hline yes & $4.8 \%(24 / 496)$ & $17.9 \%(12 / 67)$ & \\
\hline T-stage $\mathrm{BCa}$ at initial diagnosis & & & $<0.0001^{\S}$ \\
\hline pTa & $45.9 \%(253 / 551)$ & $17.1 \%(13 / 76)$ & \\
\hline pT1 & $28.7 \%(158 / 551)$ & $43.4 \%(33 / 76)$ & \\
\hline pT2 & $25.4 \%(140 / 551)$ & $39.5 \%(30 / 76)$ & \\
\hline miscellaneous & $1.6 \%(9 / 560)$ & $1.3 \%(1 / 77)$ & \\
\hline Grading (WHO 1973) BCa at initial diagnosis & & & $\begin{array}{l}<0.0001 \S \\
\left.\text { (G1 vs. G3<0.0001"; G1 vs. G2 } 0.027^{\#} ; \text { G2 vs. G3 } 0.005^{\#}\right)\end{array}$ \\
\hline G1 & $20.6 \%(115 / 559)$ & $5.3 \%(4 / 76)$ & \\
\hline G2 & $45.6 \%(255 / 559)$ & $36.8 \%(28 / 76)$ & \\
\hline G3 & $33.8 \%(189 / 559)$ & $57.9 \%(44 / 76)$ & \\
\hline unknown & $0.2 \%(1 / 560)$ & $1.3 \%(1 / 77)$ & \\
\hline Grading (WHO 2004) BCa at initial diagnosis & & & $<0.0001^{\#}$ \\
\hline low-grade & $23.8 \%(126 / 530)$ & $5.2 \%(4 / 77)$ & \\
\hline high-grade & $76.2 \%(404 / 530)$ & $94.8 \%(73 / 77)$ & \\
\hline unknown & $5.4 \%(30 / 560)$ & $0 \%(0 / 77)$ & \\
\hline UUTUC & & & n.s. \\
\hline no & $95.5 \%(535 / 560)$ & $96.1 \%(74 / 77)$ & \\
\hline yes & $4.5 \%(25 / 560)$ & $3.9 \%(3 / 77)$ & \\
\hline
\end{tabular}

Data includes synchronous UUTUCs; $n=637$; miscellaneous includes BCa staging >pT2, pTis and PUNLMP; "miscellaneous" and "unknown" categories were excluded from statistical analyses)

$B C a$ bladder cancer, DJ double J stent, n.s. not significant, UUTUC upper urinary tract urothelial cancer, WHO World Health Organization

significantly lower OS rates than the other patients (Fig. 4b; $p<0.001$ ). Patients with nephrostomy tubes died within 5 years of the initial diagnosis of BCa.
Patients with nephrostomy tubes also had significantly lower OS rates when exclusively compared to those with DJ stents (Fig. 4c; $p<0.001$ ). 
Table 6 Parameters correlating with hydronephrosis

\begin{tabular}{|c|c|c|c|}
\hline Parameter & Hydronephrosis absent & Hydronephrosis present & $\begin{array}{l}\text { p-value } \\
\text { (\$ Chi-square; } \\
\text { \# Fisher's exact) }\end{array}$ \\
\hline T-stage $\mathrm{BCa}$ at initial diagnosis & & & $<0.0001^{\S}$ \\
\hline pTa & $45.7 \%(250 / 547)$ & $20.0 \%(16 / 80)$ & \\
\hline pT1 & $31.6 \%(173 / 547)$ & $22.5 \%(18 / 80)$ & \\
\hline pT2 & $22.7 \%(124 / 547)$ & $57.5 \%(46 / 80)$ & \\
\hline miscellaneous & $1.1 \%(6 / 553)$ & $4.8 \%(4 / 84)$ & \\
\hline Grading (WHO 1973) BCa at initial diagnosis & & & $0.012^{\S}$ \\
\hline G1 & $19.7 \%(109 / 553)$ & $12.2 \%(10 / 82)$ & \\
\hline G2 & $45.8 \%(253 / 553)$ & $36.6 \%(30 / 82)$ & \\
\hline G3 & $34.5 \%(191 / 553)$ & $51.2 \%(42 / 82)$ & \\
\hline unknown & $0 \%(0 / 553)$ & $2.4 \%(2 / 84)$ & \\
\hline Grading (WHO 2004) BCa at initial diagnosis & & & $0.033^{\S}$ \\
\hline low-grade & $22.8 \%(120 / 526)$ & $12.3 \%(10 / 81)$ & \\
\hline high-grade & $77.2 \%(406 / 526)$ & $87.7 \%(71 / 81)$ & \\
\hline unknown & $4.9 \%(27 / 553)$ & $3.6 \%(3 / 84)$ & \\
\hline Type of urinary drainage & & & $<0.0001^{\#}$ \\
\hline DJ & $100 \%(38 / 38)$ & $50.0 \%(36 / 72)$ & \\
\hline nephrostomy & $0 \%(0 / 38)$ & $50.0 \%(36 / 72)$ & \\
\hline
\end{tabular}

\section{Parameters correlating with hydronephrosis}

Advanced $\mathrm{T}$-staging and grading of $\mathrm{BCa}$ at initial diagnosis significantly correlated with hydronephrosis $(p<0.0001, p<0.012$ and $p<0.033$, respectively; Table 6). All nephrostomies were placed in cases of hydronephrosis; however, only half of the DJ stents were placed in cases of hydronephrosis (Table 6).

\section{Discussion}

There is a debate as to whether DJ stenting during TURBT harms patients with regard to possible metachronous UUTUC development. Why is this? On the one hand, there is the aforementioned assumption of UUTUC caused by DJ implementation via retrograde tumour cell seeding. On the other hand, not every UUTUC results in synchronous or metachronous $\mathrm{BCa}$ although there is a constant tumour cell seeding from the upper to the lower urinary tract.

The main findings of our study were: (I) patients with DJ stenting during TURBT for BCa were at increased risk for UUTUC development during follow-up, compared to patients with nephrostomies or no urinary drainage of the upper urinary tract during TURBT; (II) an increased risk of mortality in cases of nephrostomy placement for urinary drainage; and (III) a notably low incidence of metachronous UUTUC in general (1.3\%).
All patients with UUTUC and DJ stenting in our cohort developed UUTUC congruent with the stent location (Table 2). However, not every DJ stent at the time of TURBT resulted in a metachronous UUTUC. Despite the low UUTUC incidence, our results suggested that a nephrostomy tube should be placed in cases of hydronephrosis, rather than a DJ stent. The increased mortality rate in the nephrostomy group mirrored that of hydronephrosis as an unfavorable prognostic factor. However, due to the high mortality rate among nephrostomy patients, UUTUC development during longer follow-up might be anticipated. Kaplan-Meier curves showed that deaths in the nephrostomy group (Fig. 4c) and UUTUC in the DJ stenting group (Fig. 3a and b) occurred within a 5 year follow-up. Thus, it remained unclear whether the use of nephrostomy tubes during TURBT might cause UUTUC over a longer period ( $>5$ years).

There are other studies evaluating the need for, and harmful effects of, DJ stenting in BCa patients; however, the results are controversial. Notably, our study was the first to compare the potential harm caused by both DJ stents and nephrostomy tubes during TURBT for $\mathrm{BCa}$ with regard to metachronous UUTUC.

Kiss et al. also retrospectively assessed the risk of urinary drainage with either a DJ stent or nephrostomy tube for UC recurrence in the upper urinary tract [9]. Their study design is similar to ours, however there are two 
major differences. First, Kiss et al. analysed a radical cystectomy cohort ( $n=1005$; vs. TURBT cohort in our study). Second, they assessed the impact of preoperative urinary drainage (vs. intraoperative urinary drainage in our cohort, i.e. increased risk of tumour cell seeding due to cutting/resection of the tumour). In their cohort, preoperative hydronephrosis was present in $4 \%$ of the patients bilaterally and in 19\% unilaterally. Half of the patients with hydronephrosis underwent preoperative urinary drainage with either a DJ stent $(46 \%)$ or nephrostomy tube (54\%). In total, there were 3\% UUTUC recurrences, including $13 \%$ of patients with DJ stents, $0 \%$ from the nephrostomy group and 3\% from the no urinary drainage group. As such, the authors identified preoperative DJ stenting, but not hydronephrosis, as an independent risk factor for metachronous UUTUC. Consistent with our results, UUTUC-free survival was shorter in the DJ stenting group, and OS was shorter in the nephrostomy group. Consequently, Kiss et al. proposed the use of nephrostomies for preoperative urinary drainage of the upper urinary tract, when necessary [9].

A study by Chou et al. revealed ureteral orifice localisation of $\mathrm{BCa}$ in 31 out of 572 (5.4\%) patients who underwent TURBT [12], with metachronous UUTUC occurring in four $(12.9 \%)$ of these patients. DJ stents were placed in six patients due to surgical damage of the ureteral orifice during the procedure; however, there were no metachronous UUTUCs or vesicoureteral obstruction during their follow-up. On the contrary, vesicoureteral obstruction developed in three $(10 \%)$ patients without DJ stenting due to scar formation of the ureteral orifice [12].

Mano et al. also examined the outcome of ureteral orifice resection during TURBT $(n=84)$ [16]. Patients with preoperative hydronephrosis and DJ stenting during the procedure were excluded. Postoperative hydronephrosis was documented in $13 \%$ of patients, with it being due to vesicoureteral obstruction in only three patients (4\%). Only one patient showed UUTUC recurrence [16].

Altok et al. also retrospectively investigated TURBTs for BCa including the ureteral orifice $(n=138)$ [17]. There was no DJ stenting in this cohort. Synchronous and metachronous UUTUC developed in 10.1 and 5.3\% of these cases, respectively. Postoperative hydronephrosis occurred in $19.5 \%$ of the patients without preoperative hydronephrosis due to vesicoureteral reflux (47\%), disease progression including the ureteral orifice (29\%), urolithiasis (3\%), and vesicoureteral obstruction $(6 \% ; n=$ 1). Therefore, the authors recommended against routine DJ stenting during TURBT of the ureteral orifice [17].

Taken together and based in the aforementioned studies $[12,16,17]$, the rate of postoperative vesicoureteral obstruction rate due to a TURBT close to the ureteral orifice seems to be low and thus DJ stenting to protect the ureteral orifice eventually abdicable. However, these studies include only small cohorts. Larger cohorts are certainly needed to support this assumption.

Limitations of our study were its retrospective design, including the lack of information about the cause of death; therefore, cancer specific mortality was not determined. There was no information about prior manipulation of the upper urinary tract for those $\mathrm{BCa}$ patients who were diagnosed prior to 2008 and about the DJ stent dwell time. Furthermore, tumour localization, number of tumours in the bladder as well as subsequent therapies or upper urinary tract manipulations were not investigated. There was no standardized screening for an UUTUC at the time of $\mathrm{BCa}$ diagnosis. Notably, the low incidence of metachronous UUTUCs in our cohort as well as the short median follow-up need to be considered during interpretation of the results. Thus, further investigation on larger cohorts and randomised studies comparing DJ with nephrostomy tube drainage during TURBT are needed to confirm these results.

\section{Conclusions}

In conclusion, patients with DJ stenting during TURBT for BCa had an increased risk for UUTUC development during follow-up. The results indicated that a nephrostomy tube should be placed in cases of hydronephrosis, rather than DJ stent, if feasible. Previous reports demonstrated acceptably low rates of postoperative vesicoureteral obstruction during TURBT close to the ureteral orifice. Thus, DJ stenting to protect the ureteral orifice might be abdicable.

\section{Abbreviations}

BCa: Bladder cancer; CIS: Carcinoma in situ; DJ: Double J stent; n.a: not assessable; n.s: not significant; NMIBC: Non-muscle invasive bladder cancer; OS: Overall survival; PUNLMP: Papillary urothelial neoplasm of low malignant potential; SD: Standard deviation; TURBT: Transurethral resection of a bladder tumour; UC: Urothelial cancers; UKSH: University Hospital Schleswig-Holstein; UUTUC: Upper urinary tract urothelial cancer; WHO: World Health

Organization

\section{Acknowledgements}

Not applicable.

\section{Authors' contributions}

Study concept and design: MCH, LD, CAJK, MWK

Acquisition of data: MCH, LD, TO, JPS, MJPH, MK, MWK.

Analysis and interpretation of data: MCH, LD, TO, JPS, MJPH, MK, CAJK, MWK.

Drafting of the manuscript: MCH, LD, MWK.

Critical revision of the manuscript: all authors.

Statistical analysis: MCH, LD, CAJK, MWK.

Obtaining funding: $\mathrm{MCH}, \mathrm{MWK}$.

Administrative, technical, or material support: MCH, MAK, ASM, MWK.

Supervision: MAK, ASM, MWK.

Other (specify): none.

All authors have read and approved the manuscript.

Authors' information

Not applicable. 


\section{Funding}

The study was supported by a junior research grant from the University of Luebeck, Germany, to MCH. The funding comprised financial support to $\mathrm{MCH}$. University of Luebeck as funding body had no impact on study design, collection/analysis/interpretation of data or writing the manuscript.

\section{Availability of data and materials}

The datasets generated during and analyzed during the current study are not publicly available due to privacy or ethical restrictions but are available from the corresponding author on reasonable request.

\section{Ethics approval and consent to participate}

Ethical approval was obtained from the local ethics committee at the University of Luebeck (17-354A9). The need for consent was waived by the ethics committee

\section{Consent for publication}

Not applicable.

\section{Competing interests}

The authors declare that they have no competing interests.

\section{Author details}

'Department of Urology, University Hospital Schleswig-Holstein, Campus Luebeck, Ratzeburger Allee 160, 23538 Luebeck, Germany. ${ }^{2}$ Department of Urology, Medical School Hannover, Carl-Neuberg-Strasse 1, 30265 Hannover, Germany.

Received: 13 November 2019 Accepted: 11 February 2020

Published online: 21 February 2020

\section{References}

1. Rouprêt M, Babjuk M, Compérat E, et al. European Association of Urology guidelines on upper urinary tract urothelial carcinoma: 2017 update. Eur Urol. 2018;73:111-22.

2. Cosentino M, Palou J, Gaya JM, Breda A, Rodriguez-Faba O, Villavicencio-Mavrich H. Upper urinary tract urothelial cell carcinoma: location as a predictive factor for concomitant bladder carcinoma. World J Urol. 2013;31:141-5.

3. Takaoka E, Hinotsu S, Joraku A, et al. Pattern of intravesical recurrence after surgical treatment for urothelial cancer of the upper urinary tract: a single institutional retrospective long-term follow-up study. Int J Urol. 2010;17:623-8.

4. Palou J, Rodríguez-Rubio F, Huguet J, et al. Multivariate analysis of clinical parameters of synchronous primary superficial bladder cancer and upper urinary tract tumor. J Urol. 2005;174:859-61 discussion 861

5. Perlis $N$, Turker $P$, Bostrom $P J$, et al. Upper urinary tract and urethral recurrences following radical cystectomy: review of risk factors and outcomes between centres with different follow-up protocols. World J Urol. 2013;31:161-7.

6. Picozzi S, Ricci C, Gaeta M, et al. Upper urinary tract recurrence following radical cystectomy for bladder cancer: a meta-analysis on 13,185 patients. J Urol. 2012;188:2046-54.

7. Tollefson MK, Blute ML, Farmer SA, Frank I. Significance of distal ureteral margin at radical cystectomy for urothelial carcinoma. J Urol. 2010;183:81-6.

8. Volkmer BG, Schnoeller T, Kuefer R, Gust K, Finter F, Hautmann RE. Upper urinary tract recurrence after radical cystectomy for bladder cancer--who is at risk? J Urol. 2009;182:2632-7.

9. Kiss B, Furrer MA, Wuethrich PY, Burkhard FC, Thalmann GN, Roth B. Stenting prior to cystectomy is an independent risk factor for upper urinary tract recurrence. J Urol. 2017;198:1263-8.

10. Huguet-Pérez J, Palou J, Millán-Rodríguez F, Salvador-Bayarri J, VillavicencioMavrich H, Vicente-Rodríguez J. Upper tract transitional cell carcinoma following cystectomy for bladder cancer. Eur Urol. 2001;40:318-23.

11. Wright $J$, Hotaling J, Porter MP. Predictors of upper tract urothelial cell carcinoma after primary bladder cancer: a population based analysis. J Urol. 2009;181:1035-9 discussion 1039.

12. Chou EC, Lin AT, Chen KK, Chang LS. Superficial transitional cell carcinoma of the ureteral orifice: higher risk of developing subsequent upper urinary tract tumors. Int J Urol. 2006;13:682-5.

13. Divrik RT, Sahin A, Altok M, Unlü N, Zorlu F. The frequency of hydronephrosis at initial diagnosis and its effect on recurrence and progression in patients with superficial bladder cancer. J Urol. 2007;178:8026 discussion 806.
14. Hofner T, Haferkamp A, Knapp L, et al. Preoperative hydronephrosis predicts advanced bladder cancer but is not an independent factor for cancerspecific survival after radical cystectomy. Urol Int. 2011;86:25-30.

15. Oh JJ, Byun SS, Jeong CW, Kwak C, Kim HH, Ku JH. Association between preoperative hydronephrosis and prognosis after radical cystectomy among patients with bladder cancer: a systemic review and meta-analysis. Front Oncol. 2019;9:158

16. Mano R, Shoshany O, Baniel J, Yossepowitch O. Resection of ureteral orifice during transurethral resection of bladder tumor: functional and oncologic implications. J Urol. 2012;188:2129-33.

17. Altok M, Sahin AF, Gokce MI, Ekin GR, Divrik RT. Ureteral orifice involvement by urothelial carcinoma: long term oncologic and functional outcomes. Int Braz J Urol. 2017;43:1052-9.

\section{Publisher's Note}

Springer Nature remains neutral with regard to jurisdictional claims in published maps and institutional affiliations.

\section{Ready to submit your research? Choose BMC and benefit from:}

- fast, convenient online submission

- thorough peer review by experienced researchers in your field

- rapid publication on acceptance

- support for research data, including large and complex data types

- gold Open Access which fosters wider collaboration and increased citations

- maximum visibility for your research: over $100 \mathrm{M}$ website views per year

At BMC, research is always in progress.

Learn more biomedcentral.com/submissions 